\title{
On the influence of the alternation of two different cooling systems on dairy cow daily activities
}

\author{
Simona M.C. Porto, Alessandro D'Emilio, Giovanni Cascone \\ Department of Agriculture, Food and Environment, Building and Land Engineering Section, University of Catania, Italy
}

\begin{abstract}
Among the causes that influence cow welfare, heat stress induced by microclimatic conditions is one of the most relevant and many studies have investigated the efficacy of different cooling systems on animal health status. Nevertheless, the direct influence of the cooling systems on possible modifications of dairy cow behaviour has been addressed in a few studies and the related results were affected by the presence of a paddock, which gave a refuge from hot temperature. Since an alteration of the daily time budget spent by dairy cows in their usual activities can be associated with changes in their health status, this study investigated the effects of the alternation of two different cooling systems on lying, standing, and feeding behaviour of a group of dairy cows bred in a free-stall dairy house where animals had no access to a paddock. The barn was equipped with a fogging system associated with forced ventilation installed in the resting area and a sprinkler system associated with forced ventilation installed in the feeding area. The two systems were activated alternately. The results demonstrated that the management of the two cooling systems affected the analysed behaviours. Though the activation of the cooling system installed in the resting area encouraged the decu-
\end{abstract}

Correspondence: Alessandro D'Emilio, Department of Agriculture, Food and Environment, Building and Land Engineering Section, University of Catania, via S. Sofia 100, 95123 Catania, Italy.

E-mail: ademilio@unict.it

Key words: Animal welfare; breeding environment; heat stress; microclimate control.

Acknowledgements: the authors would like to thank the ALPA SS farm located in the district of Pettineo/Pozzilli in the city of Victoria (Ragusa, Italy) for having provided the dairy house where the trial was carried out.

Ethical standards: the experiment carried out in this study complied with the current Italian laws.

Received for publication: 22 June 2016.

Accepted for publication: 12 October 2016.

CCopyright S.M.C. Porto et al., 2017

Licensee PAGEPress, Italy

Journal of Agricultural Engineering 2017; XLVIII:577

doi:10.4081/jae.2017.577

This article is distributed under the terms of the Creative Commons Attribution Noncommercial License (by-nc 4.0) which permits any noncommercial use, distribution, and reproduction in any medium, provided the original author(s) and source are credited. bitus of animals in the stalls, the activation of that one of the feeding alley could not be able to influence the standing behaviour and had only a moderate positive influence on the feeding activity.

\section{Introduction}

The behaviour and health of an animal are suitable indicators of animal welfare. The World Organisation for Animal Health states that an animal is in a good state of welfare if (as indicated by scientific evidence) it is healthy, comfortable, well nourished, safe, able to express innate behaviour, and if it is not suffering from unpleasant states such as pain, fear, and distress (World Organisation for Animal Health, 2016).

With regard to barns for dairy cows, the layout of the building, the management of the herd, and the microclimate conditions inside the barn have decisive influence on health, productive and reproductive performance as well as on animal behaviour (Armstrong, 1994; Bouraoui et al., 2002; Kadzere et al., 2002; West, 2003)

In the last years, the relationship between behaviour and physiology of the cows has been subject of research studies. Specifically, the analysis of lying, standing and feeding behaviours have been objective of research because their modifications, caused by social and physical problems as consequence of the breeding environment, could be associated with changes in the reproductive and health status of dairy cows. Some studies analysed dairy cow lying behaviour because it affects the level of milk production, the foetal development during the pregnancy, and the comfort level of the barn (Rulquin and Caudal, 1992; Haley et al., 2000; Nishida et al., 2004).

Other studies focused on the daily incidence of lying and standing behaviours for oestrus detection (Firk et al., 2002) and early diagnosis of lameness (Pastell et al., 2009). Other research works focused on the monitoring and analysis of feeding behaviour with the aim to optimise intake under different feeding managements (Halachmi et al., 1998; DeVries et al., 2004; O'Driscoll et al., 2009).

Among the causes that influence cow welfare, heat stress induced by the microclimate is one of the most relevant. In this regard, many studies have been carried out on the efficacy of different cooling systems.

Some papers studied the effects of systems made by sprinklers and fans for the direct wetting of the animals coupled with forced ventilation on both cow physiology (e.g., reduction in rectal temperature, respiratory rate, dry matter intake, rumination time, lying time) and cow lactation performance (milk quality and yield) (Avendaño-Reyes et al., 2010; Berman, 2008, 2010; AvendañoReyes et al., 2012). In these studies the cooling systems were installed in the holding pen and cows returned to their pen, or went in the milking area, after the cooling treatments. Therefore, the 
cooling systems did not affect the microclimate of the feeding alley and resting area, where animals spend most hours during the day. In those trials, the direct influence of the cooling systems on lying, standing, and feeding behaviour was not investigated. Another study focused on the comparison among different kind of cooling systems and analysed the differences in thermoregulatory responses of cows, but without any analysis of the behaviour (CorreaCalderon et al., 2004).

Further two studies on the efficacy of different cooling systems included cow behaviour analysis and were carried out in free-stall dairy houses with direct access to a large unshaded hard court paddock (Frazzi et al., 2000; Calegari et al., 2012). Specifically, the last one was carried out in a free-stall dairy house equipped with two different kind of cooling systems installed in the feeding alley and in the resting area, respectively. However, this study mainly focused on evaluating the effects on cows of the delivery rate of misters installed in the resting areas bedded with two different materials, i.e., sand and straw. Furthermore, the results were affected by the presence of a paddock and no outcomes, which regarded cow presence at the feed barrier, were provided.

On the basis of the previous remarks, this paper presents the results of an experiment that aimed at investigating the effects of the alternate use of two different cooling systems on lying, standing, and feeding behaviour of dairy cows bred in a free-stall dairy house without paddock. The two cooling systems were installed in the feeding alley and in the resting area respectively.

To this purpose the behaviour of the animals was compared in two different conditions: under heat stress with the cooling systems activated and under mild climate without cooling systems.

\section{Materials and methods}

\section{The barn under study}

The experiment was carried out inside a free-stall dairy house located in Pettineo/Pozzilli $\left(37^{\circ} 01^{\prime} \mathrm{N}, 14^{\circ} 32^{\prime} \mathrm{E}\right)$ in the province of Ragusa (Sicily, Italy), at the altitude of $234 \mathrm{~m}$ above the sea level. As the experiment aimed at evaluating cow behaviour in different climatic conditions, it lasted about one year from $1^{\text {st }}$ August 2011 to $29^{\text {th }}$ July 2012. In this work, the data collected in summer and autumn period are considered, when the cooling systems were activated and turned off, respectively. The barn had a rectangularshaped plan, sized $55.60 \times 20.75 \mathrm{~m}$ with longitudinal axis NW-SE oriented. The sides facing SE, NE and NW were completely open, whereas the side facing SW was completely closed. The structure of the building was made partly by pillars and beams in reinforced concrete and partly by pillars and trusses in steel sections. The building had a gable roof with a continuous ridge vent made up of fibre-cement corrugated slabs supported by steel purlins and trusses. The resting area consisted of 64 cubicles, arranged in two rows head to head, and sub-divided into 3 areas. The cubicles were bounded on the NE by the service alley and on the SW by the feeding alley. These two alleys were connected by 6 transverse passages, which divided the 3 resting areas.

The experiment was carried out in a pen which included a resting area consisting of 16 cubicles, sized $1.20 \times 2.15 \mathrm{~m}$, with sand beddings (Figure 1) and housed 15 primiparous Friesian cows. Cows were fed ad libitum and feed was delivered at 8:00. The feeding area was cleaned once a day between 8:30-9:30 using a scraper driven by tractor. Cow milking occurred twice daily between 5:00-6:00 and 17:30-18:30.

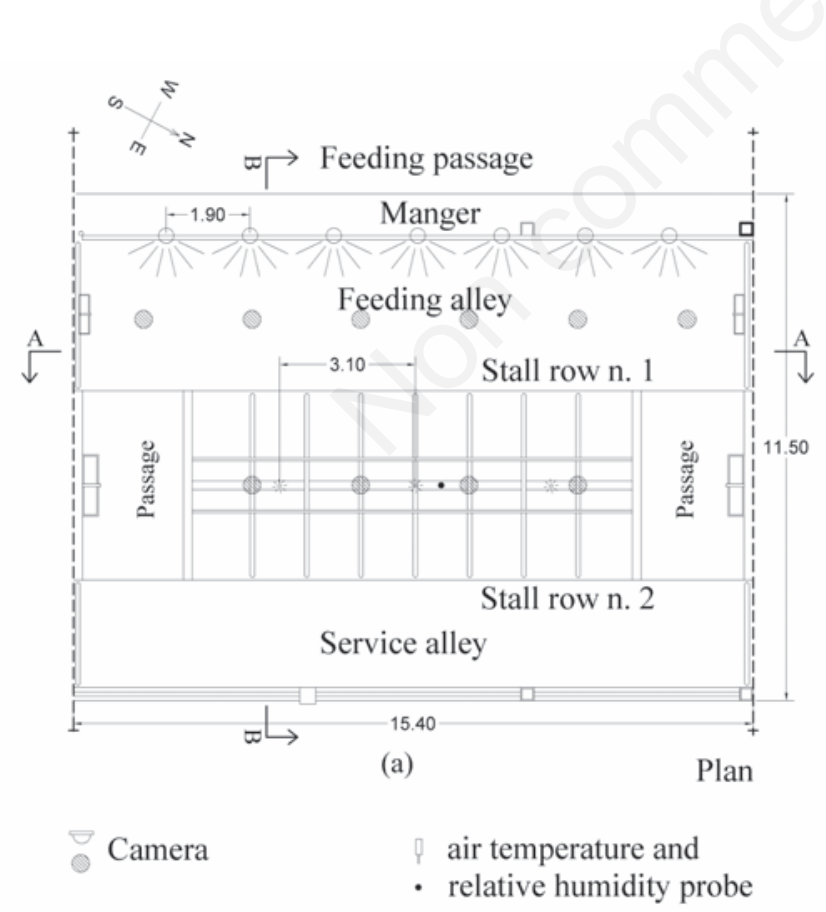

fan

$$
\text { mister } \quad 90-\text { sprinkler }
$$

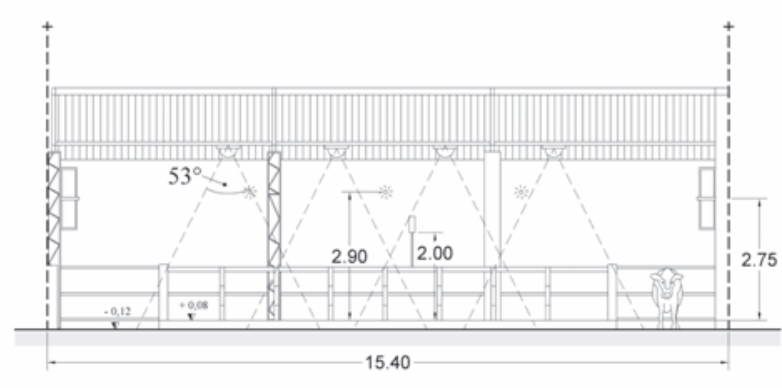

(b)

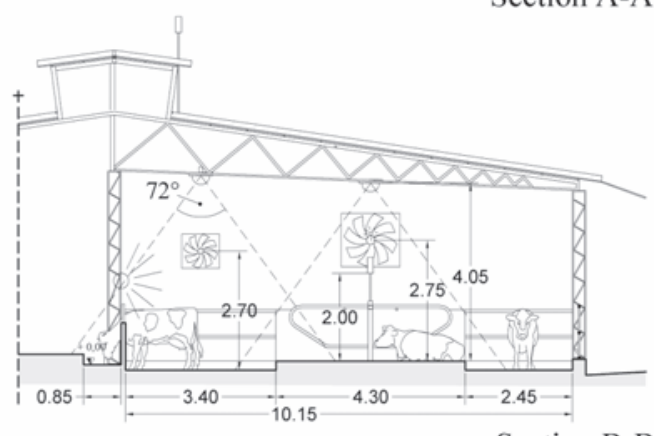

Section B-B

(c)

Figure 1. Plan (A) and cross sections (B) and (C) of the pen where the experiment was carried out. 


\section{The cooling system}

The free-stall barn was equipped with two different cooling systems (Figure 1). A fogging system associated with forced ventilation was installed in the resting area. It included 2 box fans, $1400 \mathrm{~mm}$ wide, placed above the cubicle resting area, spaced 14.00 $\mathrm{m}$ apart, with the rotation axis at $2.75 \mathrm{~m}$ above the stall floor and parallel to the longitudinal axis of the barn. The ventilation rate of each fan was $34,600 \mathrm{~m}^{3} / \mathrm{h}$. The system was completed by 3 misters placed at a height of $2.90 \mathrm{~m}$ from the floor of the stalls, spaced about $3.10 \mathrm{~m}$ apart. The operating pressure of each nozzle was 200 $\mathrm{kPa}$ and the corresponding rate was $1.01 \mathrm{~L} / \mathrm{min}$. Misters and fans were activated independently.

A sprinkler system associated with forced ventilation was installed in the feeding alley. The system was composed of 7 halfcircle $\left(180^{\circ}\right)$ sprinklers installed above the rack at a height of 2.00 $\mathrm{m}$ from the floor, spaced $1.90 \mathrm{~m}$ apart, oriented towards the feeding alley (Figure 1). The operating pressure was $200 \mathrm{kPa}$ and the rate was $2.57 \mathrm{~L} / \mathrm{min}$. The system was completed by 4 axial fans, 900 $\mathrm{mm}$ in diameter, placed above the feeding lane, spaced $14.00 \mathrm{~m}$ apart, with the rotation axis at $2.70 \mathrm{~m}$ above the floor and parallel to the longitudinal axis of the alley. The ventilation rate was 22,250 $\mathrm{m}^{3} / \mathrm{h}$. Sprinklers and fans were driven separately by a two-way controller.

During the experiment, the activation of the two systems was not simultaneous. The activation timetable is reported in Table 1. If the air temperature inside the barn was less than $27^{\circ} \mathrm{C}$, the fans of the fogging system operated for 5 min every $20 \mathrm{~min}$, otherwise they were always on. The sprinklers became operative for $15 \mathrm{sec}-$ onds every 1.5 min when the air temperature was higher than or equal to $29^{\circ} \mathrm{C}$. If the air temperature inside the barn was less than $25^{\circ} \mathrm{C}$, the fans of the sprinkler system operated for 5 min every 20 min, otherwise they were always on. The sprinklers became operative for $12 \mathrm{~s}$ every $5 \mathrm{~min}$ when the air temperature was greater than or equal to $29^{\circ} \mathrm{C}$. The fans were automatically switched off during wetting to avoid the scattering of water.

Both the systems were manually switched off during the two milking sessions and the cleaning of the feeding alley.

\section{Behaviour analysis and heat stress indices}

Dairy cow behaviour was studied by the computer-vision based system for the automatic detection of dairy cow behaviour in free-stall barns developed in previous studies (Porto et al., 2013, 2015). The computer-vision based system was composed of a multi-camera video-recording system and a software component, which executes cow behaviour detectors modelled by using the Viola-Jones's algorithm.

The multi-camera video-recording system was constituted of Vivotek FD7131 (Vivotek Inc., New Tapey City, Taiwan) cameras having a maximum resolution of $640 \times 480$ pixels and the ability to capture up to $30 \mathrm{fps}$. Moreover, this camera model was equipped with HTTP interface and light emitting diode. The cameras were positioned in the barn to obtain a mosaicked panoramic top-view image of the pen under study. Therefore, 6 cameras were used to frame the feeding alley, the rack and the manger and 4 cameras to frame the resting area (Figure 1). The cameras were mounted on steel beams by means of special brackets.

The cameras were not equipped with sensors for the night vision. However, it has been observed (Matachini et al., 2011) that considering the night hours does not improve the quality of the behavioural indices. Furthermore, in the nighttime the cooling plants were turned off.

Ten-minute scan sampling interval was adopted to detect cow in the panoramic top-view video sequences. This time sampling interval is largely adopted in literature to study the dairy cow behaviours analysed in this study. The execution of the computer-vision based system allowed the detection of dairy cow behaviours with a high level of accuracy as proved by the good values of the sensitivity indices (i.e., approximately $92 \%$ for the lying behaviour and $86 \%$ for feeding and standing ones) which yielded the percentage of cow behaviours correctly classified over the total number of cow bred in the area of the barn under study (Porto et al., 2013, 2015).

Three different behaviours were analysed among those most frequently studied (Overton et al., 2002; DeVries et al., 2003a, 2003b; Fregonesi et al., 2007; Provolo and Riva, 2009; Bava et al., 2012) because they are highly related to the comfort of dairy cows: i) feeding, which refers to the standing still position of the cows in the feeding alley with the head through the rack; ii) standing, which refers to the standing still position of the cows in the alley or inside the cubicle or to the deambulation; iii) lying, which refers to all the possible decubitus position of the cows inside the cubicle. The four usual lying positions are the following: long position when the cow lies with the head outstretched forward; short position when the cow lies with the head tilted along one side of the body; narrow position when the cow lies on the sternum with the neck slightly bent, the lower limbs close to the body and the upper limbs that may be outstretched; large position when the cow lies on one side with the lower limbs relaxed.

The following behavioural indices (Overton et al., 2002; Provolo and Riva, 2009; Mattachini et al., 2011; Bava et al., 2012) were automatically computed by the computer-vision based system (Porto et al., 2013, 2015):

Cow lying index (CLI) defined as the ratio between the number of cows lying in the cubicles and the total number of cows in the barn:

CLI = cows lying in cubicles/total cows

- Cow standing index (CSI), defined as the ratio between the number of standing cows and the total number of cows in the barn:

$\mathrm{CSI}=$ standing cows $/$ total cows

- Cow feeding index (CFI), defined as the ratio between the number of feeding cows and the total number of cows in the barn:

$\mathrm{CFI}=$ feeding cows/total cows

Table 1. Timetable of the two cooling systems activation and of the cleaning and milking activities.

\begin{tabular}{llc} 
System & \multicolumn{1}{c}{ Area } & Activation time \\
Sprinkler system & Feeding alley & $09: 00-11: 00$ \\
Fogging system & Resting area & $11: 00-14: 30$ \\
\hline Sprinkler system & Feeding alley & $14: 30-17: 00$ \\
Fogging system & Resting area & $17: 00-17: 30$ \\
\hline Activity & & Tlime \\
Cleaning & & $8: 30-9: 30$ \\
Milking & & $5: 00-6: 00$ \\
& & $17: 30-18: 30$ \\
\hline
\end{tabular}


The behavioural indices were then related to the thermal stress index, named temperature humidity index (THI), which is the most frequently used in literature to assess the level of the thermal stress of dairy cows (Oliveira and Esmay, 1982; Cook et al., 2007). In this work, the THI index was calculated by the following relation (Yousef, 1985):

$\mathrm{THI}=\mathrm{T}_{\mathrm{db}}+0.36 \mathrm{~T}_{\mathrm{dp}}+41.2$

where $\mathrm{T}_{\mathrm{db}}\left({ }^{\circ} \mathrm{C}\right)$ is the dry-bulb temperature and $\mathrm{T}_{\mathrm{dp}}\left({ }^{\circ} \mathrm{C}\right)$ is the dewpoint temperature.

Climatic parameters were measured outside and inside the barn. Air temperature and humidity were measured outdoor at the ridge line of the roof. Air temperature and humidity required for the computation of the THI index were measured inside the barn by positioning electronics probes in the resting area at the height of $2.00 \mathrm{~m}$ above the cubicle floor (Figure 1). All the sensors were connected to a data-logger that read the measurements every $5 \mathrm{sec}-$ onds and recorded the corresponding average values every $5 \mathrm{~min}$.

Behavioural and thermal stress indices were correlated with the aim of identifying how the behavioural activities considered in this study, which depend on several factors, are specifically influenced by the microclimate conditions and the two cooling systems. The correlations between behavioural indices and thermal stress indices were evaluated by calculating the Pearson correlation coefficient (r) (Provolo and Riva, 2009; Matachini et al., 2011). Correlation analyses were carried out by considering the values of behavioural and thermal stress indices computed during a week characterised by the hottest summer climatic conditions, which required the activation of the cooling systems. THI values were averaged over 10-minute intervals in order to be correlated with the behavioural indices CLI, CSI and CFI, which were obtained by using 10-minute scan sampling intervals. Specifically, to demonstrate the influence of the fogging system on the lying behaviour, the correlation analysis was carried out between CLI and THI by using data recorded in the time intervals 11:00-14:30 and 17:0017:30. Conversely, to show the influence of the sprinkler system on the standing and feeding behavioural activities, the correlation analyses between CSI and THI and between CFI and THI were carried out by using data recorded in the time intervals 9:00-11:00 and 14:30-17:00. The results of these correlation analyses were compared with those obtained by considering as baseline the earliest autumnal week when the two cooling systems were turned off.

\section{Results and discussion}

The results presented in this paper regard the week from $22^{\text {nd }}$ to $28^{\text {th }}$ August 2011 (W1) that was characterised by the most severe climatic conditions occurred during the observation period. These data are compared to the ones obtained in the week from $7^{\text {th }}$ to $13^{\text {th }}$ November 2011 (W2) when the cooling system was turned off due to the mild climatic conditions. Table 2 shows the basic statistics of the climatic parameters measured during the two considered weeks.

Figure 2 shows the trend of the weekly mean values of the behavioural and thermal stress indices computed every 10-min between the time interval 6:00-20:00 for each day of the week W1. Table 3 reports the weekly mean and standard deviation values of the behavioural and thermal heat stress indices computed at 1-h interval, between 6:00 to 20:00 in the week W1. It can be seen that just after 11:00 till almost 18:00 THI mean values were always above 80 (Figure 2 and Table 3 ) and indicated a condition of moderate heat stress (Armstrong, 1994).

The graphs related to the behavioural indices were not represented between 8:10-9:30 and 17:40-18:10, since in those periods cow behavioural activities were influenced by the management of the barn carried out by the farmer. In fact, to allow the cleaning of the feeding alley, during the first time interval the animals were

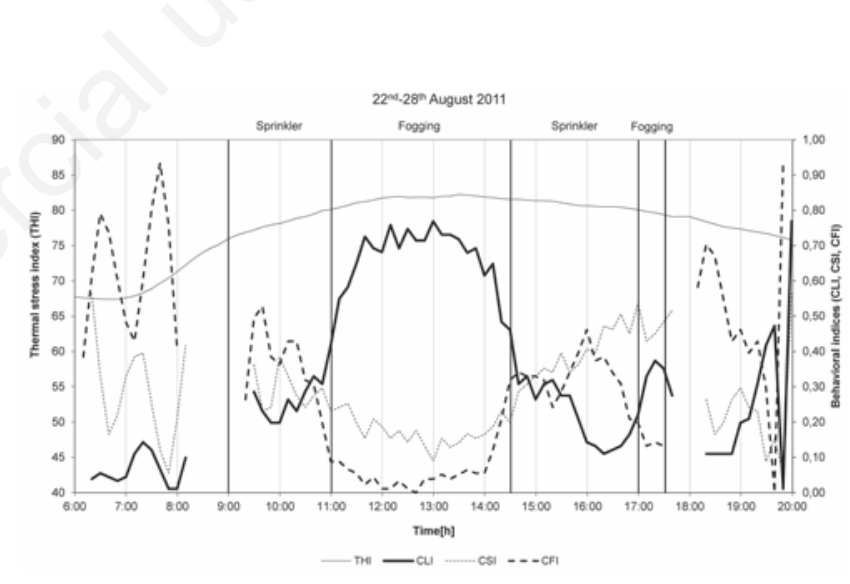

Figure 2. Weekly mean values (W1) of the behavioural and thermal stress indices computed between 6:00 and 20:00 at 10-min intervals. THI, temperature humidity index; CLI, cow lying index; CSI, cow standing index; CFI, cow feeding index.

Table 2. Statistical values of the climatic parameters and of the temperature humidity index in the two weeks considered, outside and inside the barn under study.

\begin{tabular}{|c|c|c|c|c|c|c|c|c|c|}
\hline \multicolumn{5}{|c|}{$\begin{array}{c}\text { W1 } \\
\text { 22, } 2011\end{array}$} & \multicolumn{5}{|c|}{$\begin{array}{c}\text { W2 } \\
7^{\text {th }}-13^{\text {th }} \text { November } 2011\end{array}$} \\
\hline & & & Inside & & & & & Inside & \\
\hline $\mathrm{T}\left({ }^{\circ} \mathrm{C}\right)$ & RH (\%) & $\mathrm{T}\left({ }^{\circ} \mathrm{C}\right)$ & RH(\%) & THI & $\mathrm{T}\left({ }^{\circ} \mathrm{C}\right)$ & RH(\%) & $\mathrm{T}\left({ }^{\circ} \mathrm{C}\right)$ & RH(\%) & THI \\
\hline
\end{tabular}

\begin{tabular}{lccccccccccc} 
Min & 19.5 & 20.5 & 19.9 & 29.6 & 66.3 & 9.5 & 44.7 & 10.3 & 58.1 & 55.1 & \\
Max & 35.0 & 85.6 & 35.5 & 95.3 & 83.3 & 21.9 & 44.7 & 22.8 & 99.8 & 70.4 & 58.1 \\
\hline Mean & 26.4 & 49.8 & 27.0 & 62.0 & 74.8 & 15.2 & 76.4 & 15.8 & 51.9 \\
SD & 4.5 & 15.9 & 4.9 & 16.3 & 5.2 & 3.4 & 11.5 & 3.3 & 10.6 & 4.0 \\
\hline
\end{tabular}

T, temperature; RH, relative humidity; THI, temperature humidity index; SD, standard deviation. 
confined to the area of the stall row n. 2 and the service alley (Figure 1). During the second time interval, the animals were in the milking area.

After 6:00, the cows went to the rack for feeding after being milked. Some of them, however, moved towards the cubicles or stayed in the feeding alley, because there was not enough food in the manger. Almost all the cows went to the manger at about 7:20, when the feed ration was delivered. This activity determined the daily peak of CFI at about 7:50. The subsequent decrease of CFI is due to the forced removal of the cows during the cleaning of the feeding alley. This operation strongly influenced cow behavioural activities between 9:30 and 11:00. Specifically, the graph shows a further peak of CFI at about 9:30 that was caused by the return of the animals in the feeding alley. Afterwards, a CLI increase and a CFI decrease can be observed up to 11:00 because the cows, once finished the feeding, moved from the manger towards the cubicles. In the same time interval CSI values, included in the range $0.35-$ 0.40 , showed the stay of some animals in the feeding alley.

Between 11:00 and 14:30 CLI reached its maximum values whereas CFI and CSI assumed their minimum values (Figure 2 and Table 3). This time interval was characterised by high values of air temperature inside the barn corresponding to the complete activation (fans and misters) of the cooling system in the resting area.

Between 14:30 and 17:00 a CLI decrease and a CSI increase was registered. From 17:00 a strong increase of CLI was recorded, but the lying activity of the cows was stopped at 17:30 for the second milking.

In the time interval 18:30-20:00, the graphs of Figure 2 (18:3020:00) show an increase of the CFI curve because cows after the second milking went to the manger for feeding.

Figure 3 show the trend of the weekly mean values of the behavioural and thermal stress indices computed every 10-min between the time interval 7:00-16:20 for each day of the week W2. Note that the time interval in week W2 is smaller because the cameras of the video recording system did not make possible to see the area under study without sensors for the night vision.
Similarly to what was observed in the week W1, during the week W2 the graphs related to the behavioural indices were not represented between 7:20-7:50 due to the cleaning operations. Even in this week the graph shows a peak of CFI just after the return of the animals in the feeding alley, followed by a CLI increase and a CFI decrease that can be observed up to about 10:00 due to the movement of the cows from the manger to the cubicles at the end of the feeding. Until about 15:00 the CLI curve shows values that were consistently higher than the other two indices, revealing a large and constant presence of cows in the cubicles in decubitus position. After 15:00 a CLI decrease and a CFI increase can be observed as the cows began to return to the manger.

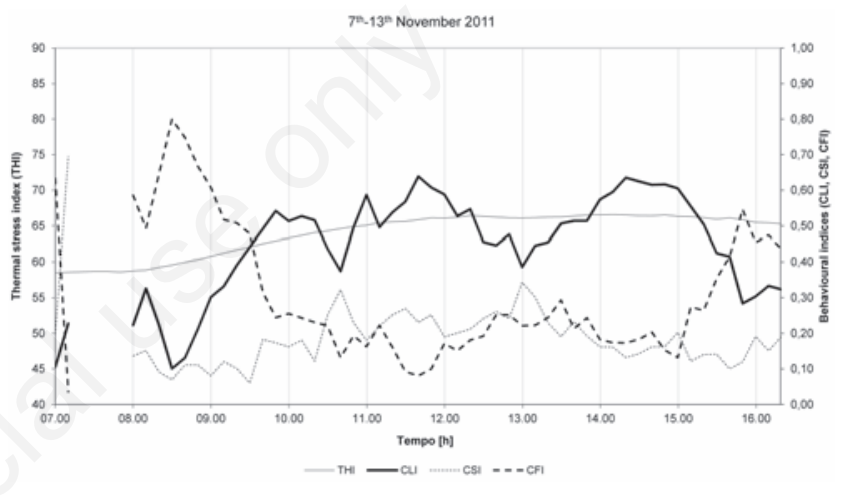

Figure 3. Weekly mean values (W2) of the behavioural and thermal stress indices computed between 7:00 and 16:20 at 10-min intervals. THI, temperature humidity index; CLI, cow lying index; CSI, cow standing index; CFI, cow feeding index.

Table 3. Weekly mean and standard deviation values of the behavioural and thermal heat stress indices computed between 6:00 and 20:00 at 1-h interval in the week W1.

\begin{tabular}{|c|c|c|c|c|c|c|c|c|}
\hline \multirow{2}{*}{ Time } & \multicolumn{2}{|c|}{ THI } & \multicolumn{2}{|c|}{ CLI } & \multicolumn{2}{|c|}{ CSI } & \multicolumn{2}{|c|}{ CFI } \\
\hline & Mean & SD & Mean & SD & Mean & SD & Mean & SD \\
\hline 6:00 & 67.8 & 0.8 & - & - & - & - & - & - \\
\hline 7:00 & 67.5 & 0.8 & 0.04 & 0.05 & 0.31 & 0.18 & 0.63 & 0.19 \\
\hline 8:00 & 69.4 & 1.4 & 0.08 & 0.10 & 0.24 & 0.22 & 0.67 & 0.27 \\
\hline 9:00 & 74.2 & 1.5 & - & - & - & - & - & - \\
\hline 10:00 & 77.4 & 0.9 & 0.23 & 0.16 & 0.30 & 0.17 & 0.42 & 0.29 \\
\hline 11:00 & 79.3 & 0.9 & 0.31 & 0.20 & 0.27 & 0.13 & 0.34 & 0.25 \\
\hline 12:00 & 81.1 & 0.9 & 0.65 & 0.14 & 0.21 & 0.10 & 0.06 & 0.08 \\
\hline 13:00 & 81.9 & 0.6 & 0.73 & 0.12 & 0.15 & 0.09 & 0.02 & 0.03 \\
\hline 14:00 & 82.0 & 0.6 & 0.69 & 0.15 & 0.15 & 0.11 & 0.05 & 0.05 \\
\hline 15:00 & 81.6 & 0.6 & 0.42 & 0.19 & 0.26 & 0.14 & 0.23 & 0.17 \\
\hline 16:00 & 81.0 & 0.9 & 0.25 & 0.13 & 0.37 & 0.11 & 0.32 & 0.17 \\
\hline 17:00 & 80.4 & 0.9 & 0.15 & 0.12 & 0.47 & 0.20 & 0.35 & 0.19 \\
\hline 18:00 & 79.4 & 0.7 & - & - & - & - & - & - \\
\hline 19:00 & 77.9 & 0.8 & 0.13 & 0.12 & 0.24 & 0.12 & 0.59 & 0.19 \\
\hline 20:00 & 76.5 & 0.8 & - & - & - & - & - & - \\
\hline
\end{tabular}

THI, temperature humidity index; CLI, cow lying index; CSI, cow standing index; CFI, cow feeding index; SD, standard deviation. 
Table 4 reports the results of the Pearson bivariate correlation between the environmental data and the behavioural indices of the animals for both the weeks W1 and W2. Also in this case the time intervals in week W2 are a bit smaller because of the use of cameras without sensors for the night vision.

In the week W1, if the time intervals corresponding to the activation of the fogging system are considered (11:00-14:30 and 17:00-17:30), $r$-value between CLI and THI was $+0.461(\mathrm{P}<0.001)$ (Table 4). This result shows that with the increase of heat stress, the animals preferred to lie on the cubicles rather than to stand or feed. Moreover, the positive correlation between THI and CLI is opposite to the results of other studies carried out in dairy houses without cooling systems (Zähner et al., 2004; Matachini et al., 2011) which reports a decrease of the lying activity in correspondence with an increase of THI. The results also show that, in this time interval when only the fogging system in the cubicle area is activated, there is a negative correlation between THI and both CSI and CFI. All these circumstances suggest that the fogging system was able to influence the animal behaviour by inducing cows to stay in the cubicles. This assumption is also supported by the results obtained by the correlation analyses carried out for the week W2, when the fogging system was turned off. Indeed, in this case all the correlations between THI and the behavioural indices are opposite to the ones obtained in week W1 when the system was turned on. It is relevant to note that the previous results show moderate correlations among the analysed variables, although all statistically significant, because the cow behaviour during the day is affected by several other factors. When the time intervals corresponding to the activation of sprinkler system are considered (9:00-11:00 and 14:30-17:00), during the week W1 $r$-value computed between THI and CSI was $+0.236(\mathrm{P}<0.002)$ (Table 4$)$. This correlation value, unlike that one calculated when the fogging system was activated, is positive and, therefore, it shows that the tendency of the animals to stay in standing position increased with the heat stress. However, since the corresponding $r$ value obtained in week W2, equal to $+0.265(\mathrm{P}<0.001)$, is almost the same obtained in week W1, it can be hypothesised that the sprinkler system could not be able to influence the standing behaviour.

In the same time interval, the negative $r$ value between THI and CFI obtained during the week W1, equal to $-0.194(\mathrm{P}<0.01)$, confirms that the feeding activity decreased with an increase of THI, as reported in other studies (Schneider et al., 1988; Cook et al., 2007). However, this negative correlation is less strong than the corresponding one calculated for the week W2, equal to -0.393
$(\mathrm{P}<0.001)$. These induce to suppose that the sprinkler system installed in the feeding alley had a moderate positive influence on the feeding activity.

The study of the effects of alternation of the two cooling systems on animal behaviour could be helpful to obtain useful information for a better management of the herd. Figure 2 show that an inappropriate use of the two cooling systems could have adverse consequences on animal behaviour. Specifically, from 9:00 to 11:00, when the sprinkler system is activated, more than $50 \%$ of the cows are at the manger, whereas from 11:00 to 14:30, when the sprinkler system is switched off and the fogging system is activated, the cows move towards the cubicles and the CLI reaches a value near $80 \%$. At $14: 30$ the sprinkler system is activated again and the animals gradually stop the lying activity. However, the objective of the farmer to increase the feeding activity is not fully pursued, because only about $35 \%$ of cows go to the manger, while $50 \%$ stay in standing still position in the feeding alley only to take advantage of the well-being determined by direct wetting of their body and the remaining $15 \%$ keep in the cubicles.

The above considerations induce to presume that an increase of the lying activity of the cows could be obtained by protracting the activation time of the fogging system. Several authors report the benefit of lying time on the cow comfort, health and production and suggest about $14 \mathrm{~h} /$ day as optimal duration (Calegari et al., 2012). Consequently, the extension of the lying activity obtained with a different timing of the cooling system could improve the well being of the cows and, therefore, their production and health.

\section{Conclusions}

This paper studied the behavioural responses of dairy cows housed in a free-stall barn without paddock in consequence of the alternate use of cooling systems in feeding alley and in resting area. The two cooling systems were a fogging system associated with forced ventilation installed in the resting area and a sprinkler system associated with forced ventilation installed in the feeding alley. The two systems were activated alternately.

The good correlation found between the CLI index and the activation of the fogging system in the resting area during the central hours of the daytime suggests that the use of such a system encourages the decubitus of dairy cows in the cubicles.

Conversely, the activation of the sprinkler system installed in the

Table 4. Correlation coefficients and significant levels found between temperature humidity index and the behavioural indices (cow lying, standing and feeding indices) for weeks W1 and W2.

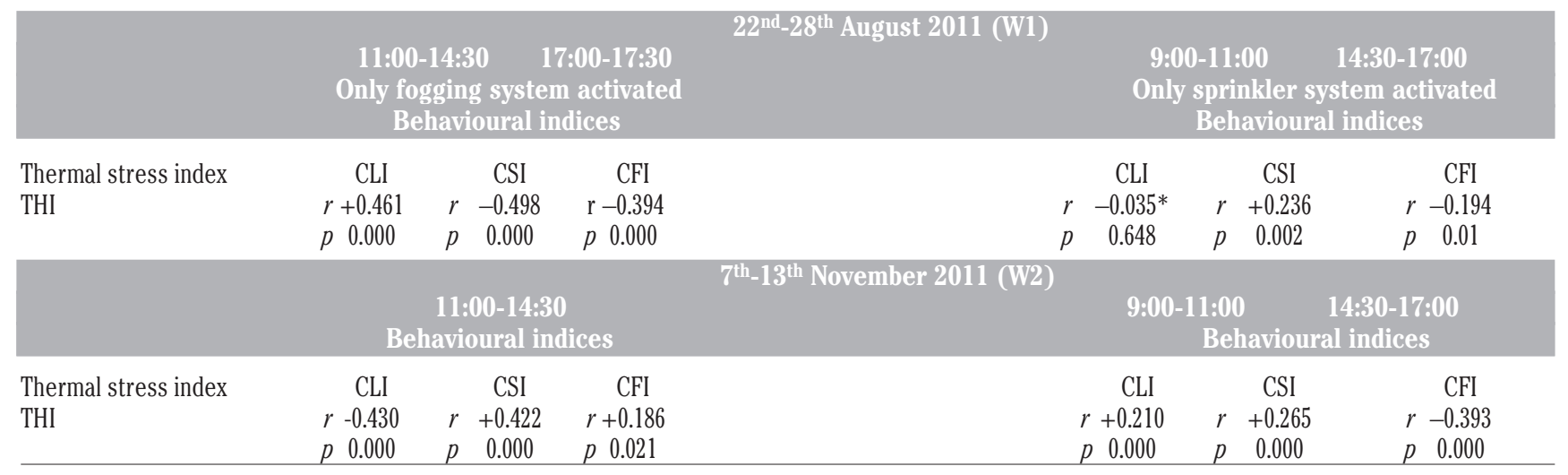

CLI, cow lying index; CSI, cow standing index; CFI, cow feeding index; THI, temperature humidity index. *Not significant level. 
feeding alley could not be able to influence the standing behaviour and had only a moderate positive influence on the feeding activity. These results suggest that the management of the cooling systems affects the overall time spent by cows in their activities. Specifically, an incorrect timing of the systems could cause a decrease of the lying time of the cows with possible negative effects on their health and milk production. It follows that the setting of the cooling systems in the barn and their timing should be supported by a behavioural analysis in order to verify the benefit on the animal.

\section{References}

Armstrong D.V. 1994. Heat stress interaction with shade and cooling. J. Dairy Sci. 77:2044-50.

Avendaño-Reyes L., Álvarez-Valenzuela F.D., Correa-Calderón A., Algándar-Sandoval A., Rodríguez-González E., Pérez-Velázquez R., Macías-Cruz U., Díaz-Molina R., Robinson P.H., Fadel J. C. 2010. Comparison of three cooling management systems to reduce heat stress in lactating Holstein cows during hot and dry ambient conditions. Livestock Sci. 132:48-52.

Avendaño-Reyes L., Hernández-Rivera J.A., Álvarez-Valenzuela F.D., Macías-Cruz U., Díaz-Molina R., Correa-Calderón A., Robinson P. H., Fadel J. G. 2012. Physiological and productive responses of multiparous lactating Holstein cows exposed to short-term cooling during severe summer conditions in an arid region of Mexico. Int. J. Biometeorol. 56:993-99.

Bava L., Tamburini A., Penati C., Riva E., Mattachini G., Provolo G., Sandrucci A. 2012. Effects of feeding frequency and environmental conditions on dry matter intake, milk yield and behaviour of dairy cows milked in conventional or automatic milking systems. Ital. J. Animal Sci. 11:230-5.

Berman A. 2008. Increasing heat stress relief produced by coupled coat wetting and forced ventilation. J. Dairy Sci. 91:4571-8.

Berman A. 2010. Forced heat loss from body surface reduces heat flow to body surface. J. Dairy Sci. 93:242-8.

Bouraoui R., Lahmar M., Majdoub A., Djemali M., Belyea R. 2002. The relationship of temperature-humidity index with milk production of dairy cows in a Mediterranean climate. Animal Res. 51:479-91.

Calegari F., Calamari L., Frazzi E. 2012. Misting and fan cooling of the rest area in a dairy barn. Int. J. Biometeorol. 56:287-95.

Cook N.B., Mentink R.L., Bennett T.B., Burgi K. 2007. The effect of heat stress and lameness on time budgets of lactating dairy cows. J. Dairy Sci. 90:1674-82.

Correa-Calderon A., Armstrong D., Ray D., DeNise S., Enns M., Howison C. 2004. Thermoregulatory responses of Holstein and Brown Swiss heat-stressed dairy cows to two different cooling systems. Int. J. Biometeorol. 48:142-8.

DeVries T.J., Von Keyserlingk M.A.G., Weary D.M. 2004. Effect of feeding space on the inter-cow distance, aggression, and feeding behavior of free-stall housed lactating dairy cows. J. Dairy Sci. 87:1432-8.

DeVries T.J., Von Keyserlingk M.A.G., Weary D.M., Beauchemin K.A. 2003a. Measuring the feeding behavior of lactating dairy cows in early to peak lactation. J. Dairy Sci. 86:3354-61.

DeVries T.J., Von Keyserlingk M.A.G., Weary D.M., Beauchemin K.A. 2003b. Technical note: Validation of a system for monitoring feeding behavior of dairy cows. J. Dairy Sci. 86:3571-4.

Firk R., Stamer E., Junge W., Krieter J. 2002. Automation of oestrus detection in dairy cows: a review. Livestock Prod. Sci. 75:219-32.
Frazzi E., Calamari L., Calegari F., Stefanini L. 2000. Behavior dairy cows in response to different barn cooling systems. Trans. ASAE. 43:387-94.

Fregonesi J.A., Veira D.M., Von Keyserlingk M.A.G., Weary D.M. 2007. Effects of bedding quality on lying behavior of dairy cows. J. Dairy Sci. 90:5468-72.

Halachmi I., Edan Y., Maltz E., Peiper U.M., Moallem U., Brukental I. 1998. A real-time control system for individual dairy cow food intake. Comput. Electr. Agric. 20:131-44.

Haley D.B., Rushen J., de Passilé A.M. 2000. Behavioural indicators of cow comfort: activity and resting behaviour of dairy cows in two types of housing. Canad. J. Animal Sci. 80:257-63.

Kadzere C.T., Murphy M.R., Silanikove N., Maltz E. 2002. Heat stress in lactating dairy cows: a review. Livestock Prod. Sci. 77:59-91.

Mattachini G., Riva E., Provolo G. 2011. The lying and standing activity indices of dairy cows in free-stall housing. Appl. Animal Behav. Sci. 129:18-27.

Nishida T., Hosoda K., Matsuyama H., Ishida M. 2004. Effect of lying behavior on uterine blood flow in cows during the third trimester of gestation. J. Dairy Sci. 87:2388-92.

O’Driscoll K., Boyle L., Hanlon A. 2009. The effect of breed and housing system on dairy cow feeding and lying behaviour. Appl. Animal Behav. Sci. 116:156-62.

Oliveira J.L., Esmay M.L. 1982. System model analysis of hot housing for livestock. Trans. ASAE. 82:1355-9.

Overton M.W., Sischo W.M., Temple G.D., Moore D.A. 2002. Using time-lapse video photography to assess dairy cattle lying behavior in a free-stall barn. J. Dairy Sci. 85:2407-13.

Pastell M., Tiusanen J., Hakojärvi M., Hänninen L. 2009. A wireless accelerometer system with wavelet analysis for assessing lameness in cattle. Biosyst. Engine. 104:545-51.

Porto S.M.C., Arcidiacono C., Anguzza U., Cascone G. 2013. A computer vision-based system for the automatic detection of lying behaviour of dairy cows in free-stall barns. Biosyst. Engine. 115:184-94.

Porto S.M.C., Arcidiacono C., Anguzza U., Cascone G. 2015. The automatic detection of dairy cow feeding and standing behaviours in free-stall barns by a computer vision-based system. Biosyst. Engine. 133:46-55.

Provolo G., Riva E. 2009. One year study of lying and standing behaviour of dairy cows in a free-stall barn in Italy. J. Agricult. Engine. 2:22-33.

Rulquin H., Caudal J.P. 1992. Effects of laying or standing on mammary blood flow and heart rate of dairy cows. Annal. Zootech. 41:101.

Schneider P.L., Beede D.K., Wilcox C.J. 1988. Nycterohemeral patterns of acid-base status, mineral concentrations and digestive function of lactating cows in natural or chamber heat stress environments. J. Animal Sci. 66:112-5.

West J.W. 2003. Effects of heat-stress on production in dairy cattle. J. Dairy Sci. 86:2131-44.

World Organisation for Animal Health. 2016. Terrestrial animal health code. Vol. 1, Chapter 7.1. Available from: http://www.oie.int/index.php?id=169\&L=0\&htmfile=chapitre _aw_introduction.htm

Yousef M.K. 1985. Stress physiology in livestock. CRC Press, Boca Raton, FL, USA.

Zähner M., Schrader L., Hauser R., Keck M., Langhans W., Wechsler B. 2004. The influence of climatic conditions on physiological and behavioural parameters in dairy cows kept in open stables. Animal Sci. 78:139-47. 